Case Report

\title{
HIGH SACRAL HIATUS WITH NON FUSION OF LAMINA OF FIRST SACRAL VERTEBRAE: A CASE REPORT
}

\author{
Vishal K., Vinay K.V., Remya K., Arunachalam Kumar \& Shishir K. \\ Department of Anatomy, K. S. Hegde Medical Academy, M angalore, Karnataka. India. \\ Correspondence: \\ Dr. Vishal Kumar, \\ Associate Professor, Department of Anatomy, \\ K.S. Hegde M edical Academy, Deralakatte, M angalore - 575 018, Karnataka, India. \\ M obile : +91 98453 58754, E-mail : vishalanat@ gmail.com.
}

\section{Abstract:}

Sacrum is a large triangular bone, forming postero-superior wall of the pelvic cavity. During the routine study of bones in the department of Anatomy, an unusual variation in the sacrum was noted. The bone showed high sacral hiatusi.e., at the level of $3^{\text {rd }}$ sacral vertebrae and non-fusion of lamina of $1^{\text {st }}$ sacral vertebrae. This type of anomaly is very rare, which prompted us to report the case. The knowledge about this rare variation is important for orthopaedicians and anesthetists since the high sacral hiatus may lead to clinical procedural failures. It is also important for accurate diagnosis of patients with low back pain. Non-fusion of lamina of $1^{\text {st }}$ sacral vertebrae may be associated with spina bifida occulta and may lead to painful condition of back.

Keywords: Vertebrae, Sacral Hiatus, Low back pain.

\section{Introduction:}

The sacrum is a large, triangular fusion of five vertebrae and forms posterosuperior wall of the pelvic cavity, wedged between two hip bones. Its blunted, caudal apex articulates with coccyx and its superior base with $5^{\text {th }}$ lumbar vertebra at the lumbosacral angle. The spines of sacral vertebrae are fused with each other median sacral crest with four or three sacral tubercles. Below the fourth tubercle there is an arched sacral hiatus in the posterior wall of the sacral canal. This hiatus is produced by the failure of the laminae of the 5 th sacral vertebra to meet in the median plane ${ }^{1}$. If the laminas of the higher sacral vertebra are not fused, then there will be a high sacral hiatus. This kind of anatomical variation in the sacral hiatus may lead to failure of caudal epidural analgesia, transpedicular and lateral mass screw placement failure ${ }^{2}$. Sacral hiatus is used as a Access this article online Quick Response Code landmark to give caudal epidural analgesia ${ }^{3}$. If there is non - fusion of laminae of all the sacral vertebrae, there will be a midline gap ${ }^{4}$. In spina bifida occulta, the
Figure-1. Posterior view of the Sacrum showing the non fusion of the lamina of the $1^{\text {st }}$ Sacral vertebra (L) and high Sacral hiatus at the level of $3^{\text {rd }}$ Sacral vertebra $(H)$.

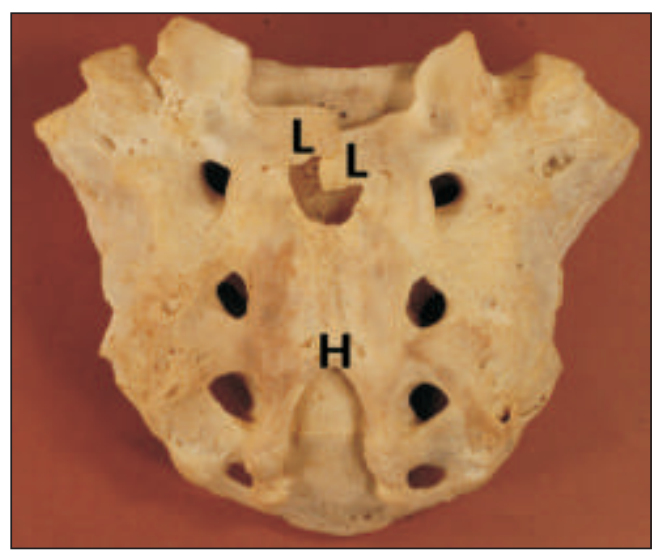

L- Non-fusion of lamina I sacral vertebra.

$\mathrm{H}$ - Sacral hiatus at III sacral vertebra.

Figure-2. Superior view of the Sacrum showing overriding of the left lamina of Sacrum over the right lamina of the 1st sacral vertebra.

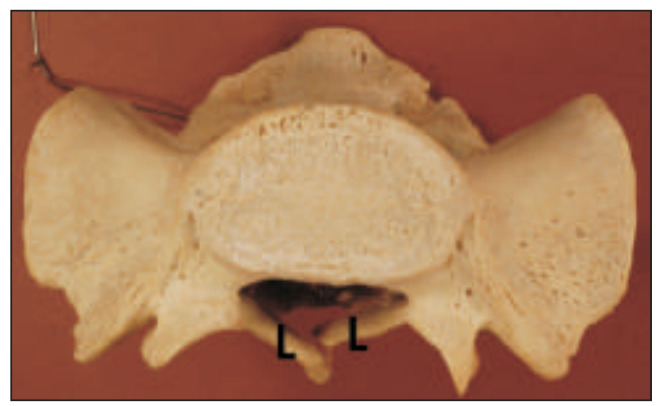

L- Non-fusion of lamina I sacral vertebra 
posterior elements of upper sacral vertebrae fail to fuse. ${ }^{5}$, ${ }^{6}$. These kind of anatomical variations will lead to painful condition of the back ${ }^{5}$ and some clinical procedural failures ${ }^{7}, 8$. Thus the knowledge of this anomaly should be kept in mind especially by anaesthetists and orthopaedicians while performing surgical procedures.

\section{Case Report:}

During the routine study of bones in the department of Anatomy at K. S. Hegde Medical Academy, Mangalore, Karnataka, we observed an unusual high sacral hiatus i.e., upto level of $3^{\text {rd }}$ sacral vertebra (Figure 1 ) and non-fusion of lamina of $1^{\text {st }}$ sacral vertebra (Figure 2). The Sacral hiatus was inverted V shaped. The lamina of the 1st sacral vertebra was not fused and the sacral spine was absent. The lamina of left side was projecting over the right lamina of right side (Figure 2). No other unusual feature of the sacrum wasfound.

\section{Discussion :}

The development of sacrum resembles the ossification of a typical vertebrae. The secondary centers of ossification appears after puberty and all the sacral vertebrae start fusing with each other. Any defect in the formation of the primary centers (which give rise to the formation of each half vertebral arch) will lead to incomplete formation of sacral canal and incomplete ossification of the laminae ${ }^{1}$.

The sacral hiatus is usually triangular in outline with apexat the level of body of $4^{\text {th }}$ sacral vertebra and the base is at the level of $5^{\text {th }}$ sacral vertebra, however the hiatus of the sacral canal is variable in extent and form. In $45 \%$ of cases, the apex of sacral hiatus is located at the level of S3 and S4 vertebra ${ }^{9}$. The knowledge about shape and extent of sacral hiatus is important because, it is the site where caudal analgesia is given in urology, proctology, general surgery and obstetrics \& gynecology ${ }^{3}$. However knowledge of anatomical confirmation and common structural modification of sacral hiatus is essential for a successful procedure ${ }^{9}$. Sacral hiatus is the site for administration of epidural anesthesia. The reliability and success of caudal epidural anesthesia depend upon anatomical variations of the sacral hiatus ${ }^{4,7,8,10}$. In about 12 to $15 \%$ of the cases, the sacral hiatus starts at S3 vertebra.

The caudal epidural block is widely used for the diagnosis \& treatment of lumbar $\&$ spinal disorders by orthopaedicians with success rate of $70-80 \%$. In about $7.7 \%$ of cases the caudal epidural block fails due to the absence of sacral hiatus $^{4}$.

Many authors have explained the different shapes of sacral hiatus. In the present case, the shape of sacral hiatus was inverted $\mathrm{V}$ shaped extending upto $3^{\text {rd }}$ sacral vertebra. The percentage of inverted $V$ shaped sacral hiatus observed by different authors were Vishal Kumar et al., (39.6\%) ${ }^{7}$, Kumar et al., $(60.3 \%)^{11}$, Nagar SK $(27 \%)^{10}$. The non-fusion of the lamina of the $1^{\text {st }}$ sacral vertebra can be found in spina bifida occulta, which occurs due to a deficiency of folic acid during pregnancy ${ }^{6}$. It is found in about $8.5 \%$ of the cases. These kind of anomaly can lead to low back ache, due to pressure of spinous processes of the $5^{\text {th }}$ lumbar vertebra on the nerve roots through the membrane closing spina bifida ${ }^{12}$. Additionally, lack or hypoplasia of posterior elements in spina bifida occulta can also lead to low back ache.

\section{Conclusion:}

The high sacral hiatus with non fusion of lamina of $1^{\text {st }}$ sacral vertebra is a rare deformity. A comprehensive awareness and understanding of the lesion and its signs and symptoms will help the orthopaedicians dealing with the case of back pain. It is helping for anaesthestists, surgeons and gyneacologists since sacral hiatus is the site where caudal analgesia and epidural anaesthesia are given. 


\section{References:}

1. Susan S et al., Gray's Anatomy. The Anatomical basis of clinical practice, 39th edn. 2005; pp.749-50, Churchill Livingstone, London.

2. Das S, Paul S. Spina bifida with higher position of sacral hiatus: a case report with clinical implications. Bratisl Lek Listy 2007; 108: 467-9.

3. Letterman GS, Trotter M . Variations of male sacrum; their significance in caudal analgesia. Surg Gynaecol Obstet 1944; 78: 551-5.

4. Sekiguchi M, Yabuki S, Satoh K, Kikuchi S. An anatomic study of the sacral hiatus: a basis for successful caudal epidural block. The Clinical Journal of Pain 2004; 20: 50-1.

5. Mehmet S, Johongir M M , Ali D. Evaluation of Congenital Lumbosacral Malformations and Neurological Findings in Patients with Low Back Pain, Turkish Neurosurgery 2009; 19(2): 145-8.

6. Naveen NS, Muralimanju, Vishal K, Maligi AM. Craniorachischisis totalis. Journal of Neurosciences in Rural practice 2010; 1 (1): 54-5.

7. Vishal Ket al., Sacral hiatus in relation to low back pain in South Indian population. Bratisl Lek Listy 2009; 110 (7): 436-441.

8. Brailsford JF. Deformities of lumbosacral region of spine. British Journal of Surgery. 1929; 16: 562-627. Published online: December 6 2005 8: 16 AM. DOI: 10. 1002/bjs.1800166405.

9. Trotter M , Letterman GS, Gordon S. Variations of female sacrum. Their significance in continuous caudal anaesthesia. Surg Gyneac Obstet 1944; 78: 419-24.

10. Nagar SK. A study of sacral hiatus in dry human sacra. Journal of Anatomical Society of India 2004; 53:18-21.

11. Kumar V, Pandey Sn, Bajpai RN, Jain PN, Longia GS. M orphometrical study of sacral hiatus. Journal of Anatomical Society of India 1992; 41: 7-13.

12. Anquin CE. Spina bifida occulta with engagement of the fifth lumbar spinous process. Journal of bone and joint surgery 1959; 41(B): 486 90. 